\title{
Distant Intentionality Healing (DIH): A randomized double blind study on post operative care and cost to care for complications following foot and ankle surgery
}

\author{
by Gerald T. Kuwada, MPH, NMD ${ }^{1 凶}$
}

The Foot and Ankle Online Journal 5 (1): 1

A randomized double blind study was completed to determine the efficacy of Distant Intentionality Healing (DIH) on post operative complications following foot and ankle surgery. The results indicate that there is significant difference between the control group and the group receiving DIH $p<.05$ level of significance. The cost to care for complications was also significant with the DIH complication being \$393/adverse event and the control group being \$985/adverse event. The national average is \$1388/adverse event.

Key Words: Monofilament, tuning fork, ankle reflex, superficial pain, neuropathy.

Accepted: December, $2011 \quad$ Published: January, 2012

This is an Open Access article distributed under the terms of the Creative Commons Attribution License. It permits unrestricted use, distribution, and reproduction in any medium, provided the original work is properly cited. $\odot$ The Foot and Ankle Online Journal (www.faoj.org), 2011 All rights reserved.

In 2007 US health care cost 2 trillion dollars, the most expensive health care system in the world. Yet, according to the WHO (World Health Organization) the US health care system is ranked $37^{\text {th }}$ in the world based on quality of care, fairness of the health care system and accessibility for the poor. ${ }^{1}$ Part of the cost of health care in the US is from the 45 million operations performed in 2007. Of these cases, 25 million operations were performed under general anesthesia. There were 18 million adverse events after the operations or a rate of $40 \%$. The cost to care for these adverse events was 25 billion dollars or 1,388 dollars per adverse event. ${ }^{2}$

Address correspondence to: Gerald T. Kuwada, DPM, NMD. $275 \mathrm{SW} 41^{\text {st }}$ Street, Renton, WA. 98057. Phone 425-251-9174, Fax 425-251-0758.

Email: drgeraldkuwada@qwestoffice.net.

\footnotetext{
${ }^{1}$ Private practice, 275 SW 41st street, Renton, WA 98057.
}

The most frequent complication was SSI (surgical site infection) at $40 \%$. Venous thromboemboli was second most frequent complication followed by postoperative cardiac event and fourth respiratory failure. In orthopedic cases, death occurred in about $0.92 \%$ of the operations in the US. ${ }^{3}$ The range of cost to care for adverse events was 600-50,000 dollars. Complications are not only catastrophic to the patient and family, in the US $50 \%$ of the bankruptcies filed were due to medical expenses for health care and included patients with medical insurance. $^{2}$ This is not the case for patients in Canada, England, and France who have a form of universal health care. 
Thus, if surgeons could reduce or eliminate the high complication rate substantially, this would be of great benefit to the patient and reduce the overall health care cost. Such a benefit might be possible with what is called Distant Intentionality Healing(DIH) or SHT (Samadhi Healing Technique) used by the healer.

What is Distant Intentionality Healing (DIH)? DIH is the mental intention to benefit another human being, living organism and human events. These mental intentioned techniques include prayer, Reiki, Therapeutic Touch, Samadhi Healing Technique (author uses this technique), Chi Kung and other human energy based techniques. Previous prospective randomized double blind studies have demonstrated the efficacy of DIH on postoperative pain reduction following foot and ankle surgery. ${ }^{6}$ DIH patients had significantly less pain postoperatively, more patients had complete pain relief postoperatively and greater pain reduction compared to the control group. Furthermore, other studies have shown significant benefit to patients who received DIH with autoimmune disease (AIDS) and coronary artery disease (CAD) as a result of acute myocardial infarct $(\mathrm{MI}){ }^{7,8}$

Patients receiving DIH had fewer complications, less doctor visits and took less medications contrasted to the control group with AIDS. ${ }^{7}$ Similarly, patients admitted to the hospital for acute MIs had no recurrence of MI, had less cardiac damage to the ventricle, had less complications, and recovered faster than the control group patients. ${ }^{8}$ Other healing modalities such as Reiki, Chi Kung and Therapeutic Touch have also demonstrated pain reduction post operatively for surgical patients. ${ }^{9-12}$

The first question to be answered by this study is can $\mathrm{DIH}$ reduce the incidence of postoperative complications following foot and ankle surgery compared to the control group? The second question is, can DIH decrease the cost to care for complications following foot and ankle surgery compared to the control group and the national average?

\section{Methods}

The study follows the guidelines from the Helsinki declaration of 1975 and modified version of 2000. Each patient reviewed and signed consent forms agreeing to participate in this research study. They were informed of any potential harm or side effects and the nature of the study (surgical complications). There were a total of 195 patients in this prospective study which took 4 years to complete. Eighty-seven patients had 98 surgical procedures were randomly selected for DIH -SHT group. The control group comprised of 107 patients having 125 surgical procedures performed on them. The DIH-SHT group received the healing energy twice per day for 2 minutes each session for up to 4 weeks after their surgery. The surgeon is the healer in this study and performed surgery on all 195 patients. Both groups were not informed of what group they were assigned.

The healer was not informed by the research assistant which patients were assigned to the control group or the DIH-SHT group. Table 1 lists the procedures performed on the patients. Table 2 lists the complications that were recorded for each patient in their group and what procedures were performed on them. Table 3 lists the cost of care for the control group complications and the DIH-SHT group complications. The patients in both groups were followed for a minimum of 6 months after their surgery.

The healer performed DIH (specifically called Samadhi Healing Technique or SHT) twice per day at 5 a.m. and midnight daily for the 4 week period for patients immediately after their surgeries. The healer visualized patients and with intention, projected the thought of no complications to group DIH-SHT patients even though the healer did not know who they were. The DIH-SHT group patients were not told if and when they were receiving such intentional healing during the 4 week period post operative. At the end of 6 months postoperative, complications were documented from their medical records. If there were complications, the cost of care was also documented from their medical financial records and used for calculations in Table 3 for both groups. 


\begin{tabular}{|l|l|l|}
\hline $\begin{array}{l}\text { 1. ANKLE SURGERIES (FUSION, STABILIZATION, FRACTURE, } \\
\text { REPAIR) }\end{array}$ & CONTROL GROUP-11 & SHT GROUP-4 \\
\hline 2. FOOT FUSIONS (TRIPLE, MIDFOOT, STJ) & CONTROL GROUP-6 & SHT GROUP-2 \\
\hline 3. BUNIONECTOMIES ( SIMPLE TO COMPLEX) & CONTROL GROUP-4 & SHT GROUP-10 \\
\hline 4. 1ST MTJ IMPLANTS, CHEILECTOMY & CONTROL GROUP-3 & SHT GROUP-6 \\
\hline 5. COMPLETE FASCIAL RELEASE & CONTROL GROUP-8 & SHT GROUP-3 \\
\hline 6. EXCISE MASS, NEUROMA, FOREIGN BODY & CONTROL GROUP-18 & SHT GROUP-15 \\
\hline 7. DIGITAL PROCEDURES & CONTROL GROUP-62 & SHT GROUP-52 \\
\hline 8. HARDWARE REMOVAL & CONTROL GROUP-13 & SHT GROUP-6 \\
\hline TOTAL & $\mathbf{1 2 5}$ & $\mathbf{9 8}$ \\
\hline
\end{tabular}

Table 1 List of operative procedures performed. SHT: Samadhi Healing Technique.

\section{Results}

The results indicate significantly less postoperative complication rate with $\mathrm{p}<.05$ level of significance for DIH-SHT group. There were $19.2 \%$ complication rate for the control group or 25/125 whereas, for the DIH-SHT group there was a $9.1 \%$ complication rate or $8 / 98$ patients. The types of complications were less serious in DIH-SHT group than the control group and none of these complications required hospitalization or surgery. One patient in the control group was eventually diagnosed with chronic regional pain syndrome and was referred to a pain clinic for treatment. There were no incidence of death, DVT, PE, cardiac and respiratory events or severe deep wound infections requiring hospitalization and surgery in both groups. Of the complications that did occur, 5 superficial infections were documented for the control group and 2 occurred for the DIH-SHT group. As for recurrence of the previous pathology for which surgery was performed, there were 7 in the control group and 2 for the DIH-SHT group.
The 2 in the DIH-SHT group were nail spicules after partial matrixectomy. For Table 1, of the 9 operatory categories, each operative procedure had complications for the control group. The DIH-SHT group had 4 surgical category procedures where complications were reported. There were 5 surgical categories where patients did not have complications in the DIH-SHT group. In Table 3, of the 20 complications the control group had 5/20 and the DIH group had 4/20 categories. As for the cost of caring for complications from both groups, the DIHSHT group averaged $\$ 393$ per adverse event. The control group had an average of $\$ 985 \angle$ per adverse event. The national average was $\$ 1,388 \angle$ per adverse event. The total cost of treating DIH-SHT complications was $\$ 3,536$ and for the control group the cost was $\$ 23,634$. 


\begin{tabular}{|c|c|c|c|c|}
\hline $\begin{array}{l}\text { ANKLE SURGERIES } \\
15 \text { TOTAL }\end{array}$ & $\begin{array}{l}\text { CONTROL GROUP: } \\
\text { CP-2; CRPS-1; SI-1 }\end{array}$ & CONTROL TOTAL: 4 & $\begin{array}{l}\text { SHT GROUP: } \\
\text { NONE }\end{array}$ & $\begin{array}{l}\text { SHT } \\
\text { TOTAL: } 0\end{array}$ \\
\hline $\begin{array}{l}\text { FOOT FUSIONS } \\
8 \text { TOTAL }\end{array}$ & $\begin{array}{l}\text { CONTROL GROUP: } \\
\text { R-1; AD-1 }\end{array}$ & CONTROL TOTAL: 2 & $\begin{array}{l}\text { SHT GROUP: } \\
\text { NONE }\end{array}$ & $\begin{array}{l}\text { SHT } \\
\text { TOTAL: } 0\end{array}$ \\
\hline $\begin{array}{l}\text { BUNIONECTOMIES } \\
14 \text { TOTAL }\end{array}$ & $\begin{array}{l}\text { CONTROL GROUP: } \\
\text { SI-1; R-1 }\end{array}$ & CONTROL TOTAL: 2 & $\begin{array}{l}\text { SHT GROUP: } \\
\text { AD-1 }\end{array}$ & $\begin{array}{l}\text { SHT } \\
\text { TOTAL: } 1\end{array}$ \\
\hline $\begin{array}{l}\text { 1ST MTJ IMPLANT } \\
9 \text { TOTAL }\end{array}$ & $\begin{array}{l}\text { CONTROL GROUP: } \\
\text { CP-1 }\end{array}$ & CONTROL GROUP: 1 & $\begin{array}{l}\text { SHT GROUP: } \\
\text { CP-1; AD-1 }\end{array}$ & $\begin{array}{l}\text { SHT } \\
\text { GROUP: } 2\end{array}$ \\
\hline $\begin{array}{l}\text { COMPLETE FASCIAL RELEASE } \\
11 \text { TOTAL }\end{array}$ & $\begin{array}{l}\text { CONTROL GROUP: } \\
\text { CP-2; AD-1 }\end{array}$ & CONTROL GROUP: 3 & $\begin{array}{l}\text { SHT GROUP: } \\
\text { NONE }\end{array}$ & $\begin{array}{l}\text { SHT } \\
\text { GROUP: } 0\end{array}$ \\
\hline $\begin{array}{l}\text { EXCISE MASS ETC. } \\
33 \text { TOTAL }\end{array}$ & $\begin{array}{l}\text { CONTROL GROUP: } \\
\text { SI-1 }\end{array}$ & CONTROL GROUP: 1 & $\begin{array}{l}\text { SHT GROUP: } \\
\text { SI-3; AD-1 }\end{array}$ & $\begin{array}{l}\text { SHT } \\
\text { GROUP: } 4\end{array}$ \\
\hline $\begin{array}{l}\text { DIGITAL PROCEDURES } \\
114 \text { TOTAL }\end{array}$ & $\begin{array}{l}\text { CONTROL GROUP: } \\
\text { CP-1; R-5; AD-2; } \\
\text { SI-1 }\end{array}$ & CONTROL GROUP: 9 & $\begin{array}{l}\text { SHT GROUP: } \\
\text { R-2 }\end{array}$ & $\begin{array}{l}\text { SHT } \\
\text { GROUP: } 2\end{array}$ \\
\hline $\begin{array}{l}\text { HARDWARE } \\
19 \text { TOTAL }\end{array}$ & CP-1; SI-1 & CONTROL GROUP: 2 & $\begin{array}{l}\text { SHT GROUP: } \\
\text { NONE }\end{array}$ & $\begin{array}{l}\text { SHT } \\
\text { GROUP: } 0\end{array}$ \\
\hline TOTAL: 223 & TOTAL & $24 / 125$ OR $19.2 \%$ & TOTAL & $\begin{array}{l}9 / 98 \text { OR } \\
9.1 \%\end{array}$ \\
\hline
\end{tabular}

Table 2 Number of complications per procedure. AD: Adhesion, CP: Chronic pain, CRPS: Chronic regional pain syndrome, R: Recurrence, SI: Superficial infection.

\section{Discussion}

There is a significant reduction in complication rate for the DIH-SHT group patients at $\mathrm{p}<.05$ level of significance. The costs to treat these surgical complications in this study and overall and on average were less for the DIH-SHT group compared to the control group and the national average. This suggests that the DIH and specifically the SHT technique are effective in complication reduction. Furthermore, the cost to treat the DIH-SHT complications was significantly less than the control group and the national average. This is a significant savings for our health care system potentially.

Previous studies have also corroborated significant postoperative pain reduction after foot and ankle surgery. There were no reported side effects of DIHSHT treatment, no complications, and no extra medical costs incurred by the patient. The healer (author and surgeon) uses a DIH technique as previously described as SHT or Samadhi Healing Technique. The technique incorporates meditation, Samadhi or state of higher consciousness, focus, visualization and intentionality. The DIH energy is imagined to encircle all group B or DIH group patients even though the healer does not know who these patients are. The patients are unaware of when they receive the DIH healing intention. 


\begin{tabular}{|l|c|c|}
\hline \multicolumn{1}{|c|}{ CONTROL GROUP } & $\begin{array}{c}\text { NUMBER OF } \\
\text { COMPLICATIONS }\end{array}$ & $\begin{array}{c}\text { COST TO TREAT COMPLICATIONS } \\
\text { (\$ Dollars) }\end{array}$ \\
\hline 1. CRPS (Chronic Regional Pain Syndrome) & 1 & 10,680 \\
\hline 2. CP (Chronic Pain) & 7 & 7,098 \\
\hline 3. R (Recurrence) & 7 & 2,180 \\
\hline 4. SI (Superficial Infection) & 5 & 1,180 \\
\hline 5. AD (Adhesion) & 4 & 2,496 \\
\hline \multicolumn{1}{|c|}{ TOTAL } & 24 & 23,634 \\
\hline AVE. COST: \$985/ADVERSE EVENT & & COST TO TREAT COMPLICATIONS \\
\hline SHT GROUP COMPLICATIONS & COMPLICATIONS Dollars) \\
\hline 1. R (Recurrence) & 2 & 392 \\
\hline 2. AD (Adhesion) & 4 & 2,496 \\
\hline 3. SI (Superficial Infection) & 3 & 648 \\
\hline TOTAL & 9 & $\mathbf{3 , 5 3 6}$ \\
\hline AVE. COST: \$393/ ADVERSE EVENT & & \\
\hline
\end{tabular}

Table 3 Cost to treat postoperative complications.

The specific intention of no complications is transferred to the patient's consciousness even though they are unaware that they have received the DIH energy. Not all patients were free of complications in the DIH group. This is attributed to either non-compliance by the patient regarding postoperative instructions or the patient was not susceptible to the DIH healing. Using the same DIHSHT technique in other studies by the author there was significant reduction in postoperative pain, less pain medication used, and distance didn't appear to affect the DIH-SHT effect. ${ }^{6,7}$

Currently there is no accepted physics paradigm that explains how DIH and SHT works. Recently, physicists postulated that DIH may be explained by the theory of entanglement and non-locality found in quantum mechanics. ${ }^{13}$ According to these theories, protons of complex and separate systems entangle and interact with each other. ${ }^{14}$
Thus electrons vibrating in synchrony can be separated by several inches to billion light years away and point $A$ and point $B$ will receive the same message at about the same time despite the distance between the protons or electrons. The entanglement allows the message to be sent faster than the speed of light.

A recent study revealed neurons from separate preparations connected to each other. ${ }^{14}$ The nonlocality theory reveals that there is no central location in the brain where our consciousness can be located and identified. Yet, the healer and recipient can connect as documented by EEG studies when the recipient's brain wave synchronizes with the healer's brain wave during a healing session. ${ }^{15}$ 
During mystical, meditative and spiritual states, using SPECT or single photon emission computed tomography scans showed reduced brain metabolic activity in the posterior parietal lobe during intense or peak religious moments in Tibetan meditators and Franciscan nuns. ${ }^{16}$

In another study, meditation was shown to decrease anxiety and enhance positive emotional feelings and increase the immune response. ${ }^{17}$ In five people who practiced Kundalini yoga, changes were noted in the area of the autonomic nervous system. This included the dorsolateral, prefrontal and parietal cortices, hippocampus, temporal lobe and the anterior cingulated cortex. ${ }^{18}$

Meditation is a vital part of SHT used by the author. It is preparatory prior to connecting to the patient and allows the healer to move into Samadhi or higher consciousness. During Samadhi, the patient is connected to the healer consciously and the intention is directed to the patient in the form of no complication for the patient after surgery.

In a landmark study by Achterberg et al., using functional MRI on 11 recipients paired with 11 different healers of various DIH disciplines, found that the anterior and middle cingulated, frontal lobes and precuneus were activated by the healers in their recipients. ${ }^{19}$ The anterior and middle cingulated are associated with control and decision making for verbal and motor responses. The frontal lobe is regarded as the information processing center, judgment and decision making. The precuneus is associated with a wide spectrum of highly integrated neural tasks including visiospatial imagery, episodic memory retrieval, self-processing operations and rest. It has been found that the posterior medial precuneus has one of the highest resting metabolic rates or hot spots in the brain. It has been hypothesized that selective hypometabolism in this area of the brain occurs during a wide range of altered states of consciousness such as sleep, drug induced anesthesia, and various vegetative states. ${ }^{20}$ It is postulated that this highly integrated neuronal network connects the autonomic and endocrine systems during $\mathrm{DIH}$ enhancing its intention within the recipient.
Achterberg did not perform functional Magnification Resonance Imagery (fMRI) on the healers' brain during the healing session. The various DIH techniques used in this study have not been extensively studied in terms of its efficacy and reliability, including the healers abilities.

Lastly, DIH-SHT benefits patients based on this study and others and may have more widespread applications such as augmenting other treatment modalities for various diseases such as cancer. The author will study via fMRI brain activity during SHT in both the healer and patients.

\section{Conclusion}

DIH-SHT is a real phenomena based on over 2,000 scientific studies including this one. ${ }^{14}$ The DIH-SHT technique has demonstrated repeated efficacy in postoperative pain reduction, decreased postoperative use of narcotic analgesia and decreased complications following foot and ankle surgery. Furthermore, there is evidence from functional Magnification Resonance Imagery( fMRI) and other imaging devices that DIHSHT affects certain parts of the "recipients" brain during the healing sessions.

There are other benefits using DIH-SHT technique such as no side effects, no toxicities, no complications and no deaths as a result of incorporating this modality in our postoperative management. This is a tremendous benefit that helps our patients reduce the cost of caring for expensive postoperative complications. This reduces or eliminates the burdensome medical care costs forcing patients into an untenable financial situation necessitating bankruptcy. Further studies of DIH-SHT will focus on fMRI studies on the healer's brain during the healing session and a wider application on other diseases like diabetic foot ulcers and cancers for example.

Foot and ankle surgery poses less serious surgical risks than other surgeries based on this study. A majority of procedures were digital procedures which comparatively poses less risk to patients than abdominal surgery for example. 
This skews the outcome and may be the reason for the low incidence of serious complications in foot and ankle surgeries contrasted to other major organ surgeries. However, I have seen patients lose their toes after simple digital surgeries including matrixectomies performed by other surgeons. Traumatic and careless tissue handling including compromise of the delicate circulatory network will result in loss of blood flow to the toe resulting in gangrene and eventual loss of the toe. Thus, all surgical procedures have some degree of risk to the patient including the simplest types to the most complex. Adding DIH-SHT postoperatively decreases the sequelae of complications and improves the surgical outcome significantly.

\section{References}

1. World Health Organization. World Health Report 2000. Geneva. WHO: 2000.

2. Fitzgerald, J., Kanter, G., Trelease, R., Benjamin E. Nursing Management Nov. 2007, Vol. 30, No. 11 page 35-39.

3. Bhattacharya T, Iorio R, Healy L. Rate of risk factors for acute inpatient mortality after orthopedic surgery. JBJS 2002 84: $562-572$.

4. Kuwada, GT, Distant Intentionality Healing for reduction of postoperative pain following foot and ankle surgery. A randomized, double Blind study. Submitted to the Journal of Alt. and Complementary Med. 2010. (Not published) 5. Kuwada, GT. Distant Intentionality Healing for reduction of narcotic analgesia following foot and ankle surgery. A randomized, double blind study. Submitted to the Journal of Consciousness. 2010. This is an invalid reference as it stands. 6. Sicher F, Targ E, Moore D, Smith HS. A randomized double blind study of the effect of distant healing in a population with advanced AIDs - report of a small scale study. Western Journal of Medicine. 1998 169: :356-363.

7. Harris W, Gowda M, Kolb KW, Strychacz CP, Vacek JL, Jones PG, Forker A, O'Keefe JH, McCallister BD.

A randomized, controlled trial of the effects of remote, intercessory prayer on outcomes in patients admitted to the coronary care unit. Arch Internal Medicine 1999 159: 22732278.

8. Jonas, W., Crawford, C. (eds.) Healing, Intention and Energy Medicine: Science, Research Methods and Clinical Implications. 2003. London: Harcourt.

9. Gerber, R. Vibrational Medicine. 3 $3^{\text {rd }}$ edition. 2001. Bear and Company. Rochester, VT.

10. Olson K, Hansen J. Using Reiki to manage pain: A preliminary report. Cancer Prevention Control 1997 1: 108-113. 11. Gordon R. Quantum Touch: The Power to Heal. 2002 North Atlantic Books, Berkley, CA.
12. Einstein, A., Podolsky, B., Rosen, N. Can Quantum Mechanical description of physical reality be complete? Phys. Rev. 19355:47: 777-780.

13. Pizzi R, Fantasia A, Gleain F. Non-local correlation between human neural networks. In: Donkar, E., Pirick, AR., Brandt, HE. Eds. Quantum Information and Computation II.

Proceedings of SPIE 5436:2004 107-117.

14. Charman RA. Placing healers, healees and healing into a wider research context. J Alter Complementary Medicine 2000 6: $177-180$.

15. Shealy C, Smith N, Liss T, Borgmeyer S. EEG Alterations during healing. Subtle Energies 2000 11: 241-248.

16. D'Aquila EG, Newberg AB. Mystical states and the experience of God: A model of the neuropsychological substrate. Zygon J Religion Sci 199328 177-200.

17. Davidson RJ, Kabat-Zinn J, Schumacher J, Rosenkranz M, Muller D, Santorelli SF, Urbanowski F, Harrington A, Bonus K, Sheridan JF. Alterations in brain and immune function produced by mindfulness meditation. Psychosomatic Medicine 2003 65: 564-570.

18. D'Aquila EG, Newberg AB. The neuropsychology of aesthetic, spiritual and mystical states. Zygon: J Religion Sci 2000 35: 39-51.

19. Standish L, Johnson J, Clark L, Todd R, Kozak L, Richards T. Evidence of correlated fMRI signals between distant human brains. Alt Therapies in Health 2003 9: 122-128.

20. Achterberg J. Richards T, Salomie IA, Cooke K. Individual recipients' functional brain changes during distant intentionality: a fMRI analysis. Presented at the North American Research Conference on Complementary and Integrative Medicine, May, 2006.

21. Lazar S, Bush G, Gollub RL, Fricchione GL, Khalsa G. Benson H. Autonomic Nervous System: Functional Brain Mapping of the Relaxation Response and Meditation. Lippincott,Williams \& Wilkins, Inc. 2000. 